\section{The Quest for a Clostridium difficile Vaccine, Where are we Now?}

\section{Sarah Kabbani, Michele Paine, Regina Mosley and Nadine Rouphael* $^{*}$}

Department of Medicine, Division of Infectious Diseases, The Hope Clinic of the Emory Vaccine Center, Emory University School of Medicine, Atlanta, GA, USA

\begin{abstract}
Clostridium difficile Infection is the most common acquired health care infection with significant morbidity, mortality and health care costs. Although therapy is available, recurrences are common, and vaccination would be a cost effective strategy for prevention. Three toxin based vaccine candidates are the most advanced in clinical trials for primary prevention in high risk individuals.

Keywords: Clostridium difficile, Vaccine
\end{abstract}

Clostridium difficile is an anaerobic, gram-positive, spore-forming, toxin-producing bacillus acquired through ingestion of spores after disruption of normal gut flora. The virulence factors in $C$. difficile are Toxin A and Toxin B encoded by the genes TcdA and TcdB.

C. difficile Infection (CDI) is currently the leading nosocomial infection in the US. According to the Centers for Disease Control and Prevention estimates, the yearly incidence is 453,000 cases, leading to 29,300 deaths [1]. CDI results in $\$ 4.8$ billion in excess cost in US acute care facilities annually [2]. Recent data suggest that $C$. difficile has replaced methicillin resistant Staphylococcus aureus as the most common healthcare-associated infection in some hospitals [3]. CDI was thought to be the hallmark of prolonged hospital stay and antibiotic exposure, but is now frequently seen in populations considered previously to be at low risk for infection, such as young and healthy non hospitalized individuals [4,5]. Also severe cases of CDI have been reported in peripartum women [6,7]. According to studies conducted across the United States, Canada, and the United Kingdom community-acquired cases of CDI account for $20 \%-27 \%$ of all CDI cases [8-10].

While CDI can be mild, it can also progress to a severe disease with pseudomembranous colitis and toxic megacolon requiring ICU stay,

*Corresponding author: Nadine Rouphael, Department of Medicine, Division of Infectious Diseases, The Hope Clinic of the Emory Vaccine Center, Emory University School of Medicine, Irvin Court, Atlanta, GA, USA, Tel: +1 4047121435, Fax: +1 4044999727, E-mail: nroupha@emory.edu

Citation: Kabbani S, Paine M, Mosley R, Rouphael N (2016) The Quest for a Clostridium difficile Vaccine, Where are We Now? J Vaccines Res Vaccin 2: 005.

Received: February 25, 2016; Accepted: May 30, 2016; Published: June 13, 2016 colectomy [11] and potential death. Most initial episodes respond to treatment with fidaxomicin [12], vancomycin [13], or metronidazole $[14,15]$. A decreased clinical response of $C$. difficile treated with metronidazole has been observed, but is not attributed to drug resistance [16]. Among patients with severe CDI, vancomycin is superior [13] and fidaxomicin use is associated with a lower rate of recurrences.

Approximately $15 \%-30 \%$ of patients experience a recurrence in symptoms after successful initial therapy, usually occurring in the first few weeks after treatment discontinuation [17]. Fecal transplants have been shown to be effective for treating recurrent CDI. However, the optimal route of administration and long-term effects remain unknown [18]. Prevention of CDI includes hand washing, personal protective equipment for healthcare workers, and strategic antibiotic prescribing. New methods for CDI prevention such as vaccination are needed. Early animal studies showed that administration of TcdA/B protected animal models from CDI [19]. Adequate humoral immune responses to $\mathrm{CDI}$ through production of sufficient quantity of IgG against TcdA/B has been shown to correlate with decreased likelihood of developing disease [20] and subsequent episodes [21]. Since then strategies using both passive and active immunization have been studied for the prevention and treatment of CDI. Human monoclonal antibodies CDA- 1 and CDB-2 have been tested in CDI and demonstrated a decreased risk of recurrence from $25 \%$ to $7 \%$ when compared to placebo [22-24]. However considering the cost and inconvenience of this form of therapy, it is unlikely to be used as primary prophylaxis except in very high-risk patients [25]. On the other hand, vaccines against $C$. difficile, if and when they are available, will be a cost-effective method to limit the spread of CDI [26].

The first vaccination approach was the use of the toxoid-based vaccines building on the success against other important pathogens such as Clostridium tetani and Corynebacterium diphtheria. More recent studies provided important information about the nature and localization of toxin-neutralizing epitopes and led to the use of recombinant engineered toxin fragments as vaccine candidates. While many candidates are being evaluated, only 3 are currently undergoing testing in clinical trial (Table 1).

The first vaccine, developed by Acambis and used in humans, contained formalin inactivated partially purified TcdA and TcdB adjuvanted with alum (ACAM-CDIFF ${ }^{\mathrm{TM}}$ ) [27]. In a phase 1 trial, the vaccine was safe and immunogenic in 30 subjects with $90 \%$ of them developing a serum antibody response measured by ELISA and toxin neutralization assay. The immunogenicity was increased when higher and adjuvanted doses were used. The vaccine was subsequently studied in 3 cases with recurrent CDI receiving long-term vancomycin (7-22 months). The study had a small number of subjects and was not placebo controlled but showed that the vaccine was able to induce neutralizing antibody in 2 out of the 3 vaccine recipients, none of whom had recurrent disease [28].

This vaccine candidate has undergone further purification, and was tested later by Sanofi Pasteur using highly purified formalin-inactivated alum-absorbed preparations of TcdA and B [29]. In healthy 


\begin{tabular}{|c|c|c|c|c|c|}
\hline Vaccine Formulation & Adjuvant & Company & Vaccination Regimen & Population & $\begin{array}{c}\text { Study or ClinicalTrials. } \\
\text { gov Number }\end{array}$ \\
\hline $\begin{array}{c}\text { Formalin inactivated partially } \\
\text { purified TcdA and TcdB }\end{array}$ & None/Al $(\mathrm{OH})_{3}$ & Acambis & 4 doses intramuscular & Healthy adults & [27] \\
\hline $\begin{array}{l}\text { Highly purified formalin-in- } \\
\text { activated preparations of } \\
\text { TcdA and B }\end{array}$ & $\mathrm{Al}(\mathrm{OH})_{3}$ & Sanofi Pasteur & 3 doses intramuscular & Healthy adults and elderly & $\begin{array}{c}{[29]} \\
\text { NCT01230957 } \\
\text { NCT00772343 } \\
\text { NCT01887912 }\end{array}$ \\
\hline $\begin{array}{l}\text { Genetically modified full } \\
\text { length TcdA and TcdB }\end{array}$ & $\mathrm{None} / \mathrm{Al}(\mathrm{OH})_{3}$ & Pfizer & 3 doses intramuscularly & Healthy adults and elderly & $\begin{array}{l}\text { NCT01706367 } \\
\text { NCT02052726 } \\
\text { NCT02117570 } \\
\text { NCT02561195 }\end{array}$ \\
\hline $\begin{array}{l}\text { Recombinant fusion protein } \\
\text { from truncated forms of } \\
\text { TcdA and TcdB }\end{array}$ & None/Al $(\mathrm{OH})_{3}$ & Valneva & 3 or 4 doses intramuscularly & $\begin{array}{l}\text { Healthy adults and } \\
\text { elderlty }\end{array}$ & $\begin{array}{l}\text { NCT01296386 } \\
\text { NCT02316470 }\end{array}$ \\
\hline
\end{tabular}

Table 1: Clostridium difficile vaccine candidates in clinical trials.

adults and elderly, the vaccine was shown to be safe and well tolerated. The Sanofi Pasteur vaccine induced a complete seroconversion for TcdA that was achieved at all doses in adults, and at the highest vaccine dose in the elderly. The TcdB seroconversion was lower, both in adults and elderly groups reaching $75 \%$. The antibody response appeared persistent only for TcdA in adult groups, whereas the TcdB response declined 6 months after vaccination [30] suggesting the need for a boost. Phase 2 trials that test the immunogenicity in adults for primary prevention (NCT01230957) and infected adults for prevention of recurrent disease (NCT00772343) have been completed, and currently a phase 3 trial is recruiting 15,000 adults $\geq 50$ years at risk for CDI to assess the efficacy of the vaccine (NCT01887912), 10,000 will receive the vaccine, and 5,000 will receive placebo.

Newer vaccine candidates use recombinant toxin based epitopes. The advantages of this technique are that the vaccine contains specific epitopes that enhance neutralizing antibodies, and overcomes the potential risk of incomplete inactivation of the toxins by formalin. Pfizer uses ClosTron mutagenesis procedure and a specific shuttle vector system to produce genetically modified full length TcdA and $\mathrm{TcdB}$ toxoid based vaccine from a toxin deficient $C$. difficile strain $[31,32]$. Phase 1 trials with and without alum as an adjuvant have been completed (NCT01706367 \& NCT02052726), and phase 2 trials are currently ongoing (NCT02117570 \& NCT02561195). The last vaccine candidate currently in clinical trials was developed by Valneva using a recombinant fusion protein containing cell binding domains from truncated forms of TcdA and TcdB $[32,33]$. This recombinant fusion protein was first named IC84 then VLA84 [34]. A phase 1 clinical trial with 60 adults ( 3 doses) and 81 elderly ( 4 doses) has been completed (NCT01296386), and demonstrated favorable safety and tolerability in a press release by the company. IgG Toxin A/B were induced at similar levels in adults and elderly but neutralizing antibody responses were less common in elderly when compared to adults. Enrollment for a phase 2 trial has been completed in 500 adults over age 50 the US and Germany (NCT02316470) and follow up is ongoing.

These last three vaccine candidates are being tested for primary prevention in high-risk subjects 50 years and above. The vaccine schedule is typically 3 doses by intramuscular route with the second and third doses given 1 and 4 weeks after the initial dose.

One of the main challenges in the development of an effective vaccine against $\mathrm{CDI}$, is its ability to elicit a protective immune response in the highest risk population [34]. The use of adjuvants will likely play an important role in optimizing the immune response in elderly and immunocompromised patients who are at the highest risk for disease complications [33]. Another challenge is identifying the target population for the vaccines and the need for boosting. The hope is that the next few years will witness the licensure of a safe and effective vaccine against CDI, the leading nosocomial infection in the US.

\section{Conflict of Interest}

$\mathrm{RM}$ and NR receive funds from Sanofi Cdiffense trial.

\section{References}

1. Lessa FC, Winston LG, McDonald LC; Emerging Infections Program C difficile Surveillance Team (2015) Burden of Clostridium difficile infection in the United States. N Engl J Med 372: 2369-2370.

2. Dubberke ER, Olsen MA (2012) Burden of Clostridium difficile on the healthcare system. Clin Infect Dis 55 Suppl 2: 88-92.

3. Miller BA, Chen LF, Sexton DJ, Anderson DJ (2011) Comparison of the burdens of hospital-onset, healthcare facility-associated Clostridium difficile Infection and of healthcare-associated infection due to methicillin-resistant Staphylococcus aureus in community hospitals. Infect Control Hosp Epidemiol 32: 387-390.

4. Dial S, Delaney JA, Barkun AN, Suissa S (2005) Use of gastric acid-suppressive agents and the risk of community-acquired Clostridium difficile-associated disease. JAMA 294: 2989-2995.

5. Chitnis AS, Holzbauer SM, Belflower RM, Winston LG, Bamberg WM, et al. (2013) Epidemiology of community-associated Clostridium difficile infection, 2009 through 2011. JAMA Intern Med 173: 1359-1367.

6. Rouphael NG, O'Donnell JA, Bhatnagar J, Lewis F, Polgreen PM, et al. (2008) Clostridium difficile-associated diarrhea: an emerging threat to pregnant women. Am J Obstet Gynecol 198: 635.

7. Centers for Disease Control and Prevention (2006) Severe Clostridium difficile-associated disease in populations previously at low risk - Four states, 2005. MMWR Morb Mortal Wkly Rep 54: 1201-1205.

8. Wilcox MH, Mooney L, Bendall R, Settle CD, Fawley WN (2008) A case-control study of community-associated Clostridium difficile infection. J Antimicrob Chemother 62: 388-396.

9. Kutty PK, Woods CW, Sena AC, Benoit SR, Naggie S, et al. (2010) Risk factors for and estimated incidence of community-associated Clostridium difficile infection, North Carolina, USA. Emerg Infect Dis 16: 197-204.

10. Lambert PJ, Dyck M, Thompson LH, Hammond GW (2009) Population-based surveillance of Clostridium difficile infection in Manitoba, Canada, by using interim surveillance definitions. Infect Control Hosp Epidemiol 30: 945-51.

11. Dallal RM, Harbrecht BG, Boujoukas AJ, Sirio CA, Farkas LM, et al. (2002) Fulminant Clostridium difficile: an underappreciated and increasing cause of death and complications. Ann Surg 235: 363-372. 
12. Louie TJ, Miller MA, Mullane KM, Weiss K, Lentnek A, et al. (2011) Fidaxomicin versus vancomycin for Clostridium difficile infection. N Engl J Med 364: $422-431$.

13. Zar FA, Bakkanagari SR, Moorthi KM, Davis MB (2007) A comparison of vancomycin and metronidazole for the treatment of Clostridium difficile-associated diarrhea, stratified by disease severity. Clin Infect Dis 45: 302-307.

14. Wenisch C, Parschalk B, Hasenhündl M, Hirschl AM, Graninger W (1996) Comparison of vancomycin, teicoplanin, metronidazole, and fusidic acid for the treatment of Clostridium difficile-associated diarrhea. Clin Infect Dis 22: 813-818.

15. Teasley DG, Gerding DN, Olson MM, Peterson LR, Gebhard RL, et al. (1983) Prospective randomised trial of metronidazole versus vancomycin for Clostridium-difficile-associated diarrhoea and colitis. Lancet 2: 1043-1046.

16. Rupnik M, Wilcox MH, Gerding DN (2009) Clostridium difficile infection: new developments in epidemiology and pathogenesis. Nat Rev Microbiol 7: 526536 .

17. Johnson S (2009) Recurrent Clostridium difficile infection: a review of risk factors, treatments, and outcomes. J Infect 58: 403-410.

18. Kociolek LK, Gerding DN (2016) Breakthroughs in the treatment and prevention of Clostridium difficile infection. Nat Rev Gastroenterol Hepatol 13: $150-160$.

19. Libby JM, Jortner BS, Wilkins TD (1982) Effects of the two toxins of Clos tridium difficile in antibiotic-associated cecitis in hamsters. Infect Immun 36 822-829.

20. Kyne L, Warny M, Qamar A, Kelly CP (2000) Asymptomatic carriage of Clostridium difficile and serum levels of IgG antibody against toxin $A$. N Engl J Med 342: 390-397.

21. Kyne L, Warny M, Qamar A, Kelly CP (2001) Association between antibody response to toxin $\mathrm{A}$ and protection against recurrent Clostridium difficile diarrhoea. Lancet 357: 189-193.

22. Leav BA, Blair B, Leney M, Knauber M, Reilly C, et al. (2010) Serum anti-toxin $\mathrm{B}$ antibody correlates with protection from recurrent Clostridium difficile infection (CDI). Vaccine 28: 965-969.
23. Lowy I, Molrine DC, Leav BA, Blair BM, Baxter R, et al. (2010) Treatment with monoclonal antibodies against Clostridium difficile toxins. N Engl J Med 362: 197-205.

24. Taylor CP, Tummala S, Molrine D, Davidson L, Farrell RJ, et al. (2008) Open-label, dose escalation phase I study in healthy volunteers to evaluate the safety and pharmacokinetics of a human monoclonal antibody to Clostridium difficile toxin A. Vaccine 26: 3404-3409.

25. Ghose C, Kelly CP (2015) The prospect for vaccines to prevent Clostridium difficile infection. Infect Dis Clin North Am 29: 145-162.

26. Lee BY, Popovich MJ, Tian Y, Bailey RR, Ufberg PJ, et al. (2010) The potential value of Clostridium difficile vaccine: an economic computer simulation model. Vaccine 28: 5245-5253.

27. Kotloff KL, Wasserman SS, Losonsky GA, Thomas W Jr, Nichols R, et al. (2001) Safety and immunogenicity of increasing doses of a Clostridium difficile toxoid vaccine administered to healthy adults. Infect Immun 69: 988-995.

28. Sougioultzis S, Kyne L, Drudy D, Keates S, Maroo S, et al. (2005) Clostridium difficile toxoid vaccine in recurrent $C$. difficile-associated diarrhea. Gastroenterology 128: 764-770.

29. Foglia G, Shah S, Luxemburger C, Pietrobon PJ (2012) Clostridium difficile: development of a novel candidate vaccine. Vaccine 30: 4307-4309.

30. Greenberg RN, Marbury TC, Foglia G, Warny M (2012) Phase I dose finding studies of an adjuvanted Clostridium difficile toxoid vaccine. Vaccine 30 : 2245-2249.

31. Donald RG, Flint M, Kalyan N, Johnson E, Witko SE, et al. (2013) A novel approach to generate a recombinant toxoid vaccine against Clostridium difficile. Microbiology 159: 1254-1266.

32. Swanson KA, Schmitt HJ, Jansen KU, Anderson AS (2015) Adult vaccination. Hum Vaccin Immunother 11: 150-155.

33. Leuzzi R, Adamo R, Scarselli M (2014) Vaccines against Clostridium difficile. Hum Vaccin Immunother 10: 1466-1477.

34. Rebeaud F, Bachmann MF (2012) Immunization strategies for Clostridium difficile infections. Expert Rev Vaccines 11: 469-479. 